\title{
Functional and Orthodontic Treatment of a Class II Malocclusion: Case Report
}

Saif S*

Private Practice, Morocco

Case Report

Volume 6 Issue 2

Received Date: April 28, 2021

Published Date: May 24, 2021

DOI: $10.23880 /$ oajds-16000295

Email: drsarahsaif@gmail.com

\section{Abstract}

Class II malocclusion, the distal relationship between mandibular and maxillary molars, is very frequent in the population. In growing patients it carries a great risk of dental trauma, a more negative perception of facial and dental aesthetics a negative impact on the quality of life and self-esteem, a greater predisposition to periodontal diseases and a greater incidence of sleep disorders. It has different etiologies. Thus many treatment approaches can be used to correct this condition, either an orthopedic treatment and orthodontic treatment or a combination protocol. Functional devises have been widely used for the correction of the sagittal intermaxillary relationship in growing patients, but especially in the treatment of Class II. The success of a two phase treatment depends on its initiation during the growth period and on the patient's degree of implication. This case illustrates a two phase treatment where sagittal correction was undertaken before transverse correction to make optimal use of the patient's pubertal growth spurt in first phase followed by a second phase of fixed appliance therapy during adolescence to achieve optimal results

Keywords: Functional appliances; Orthopedic treatment; Class II maloclusion

\section{Introduction}

Class II is one of the most common malocclusions, it occurs in about one third of the population. It is a medical syndrome that requires a complete clinical and radiographic examination. Skeletal Class II have multiple etiologies, therefore, there are many treatment options for correcting this malocclusion with varying degrees of clinical support [1-9]. During the last twenty years, functional appliances have been widely used for the correction of sagittal intermaxillary descrepancies in children especially with class II malocclusions. The success of the orthopedic treatment depends on the implementation of the treatment during growth period and patients cooperation.

The aim of this paper is to illustrate a two phase treatment of a class II malocclusion in a 10 years old patient.

\section{Case Presentation}

A 10 years old patient presented with as a chief complaint a retroposition of the mandibule Extraoral examination revealed, on the frontal view, a square face, with equal upper and middle facial compartments and a slight decrease in the lower compartment. A chin deviation to the right side, and a forced lip closure with a reflex of biting the lower lip were noted (Figure 1). Functional examination revealed no sign of temporomandibular joint dysfunction. Intraoral examination showed a mild oral hygiene, a bilateral infraclusia, a lower midline shift, a proclination of the two maxillary central incisors and a class II canine and molar relationship with an overbite of $2 \mathrm{~mm}$ and an overjet of $10 \mathrm{~mm}$, the spee curve was exaggerated (Figure 1). 


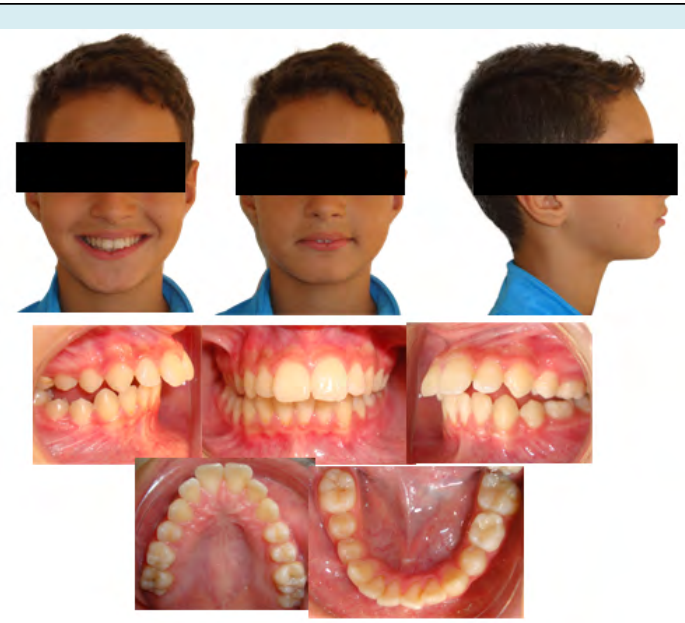

Figure 1: Pre-treatment extraoral and intraoral photographs.
Pre-treatment panoramic radiograph showed normal general structures and a stage of mixed dentition (Figure 2).
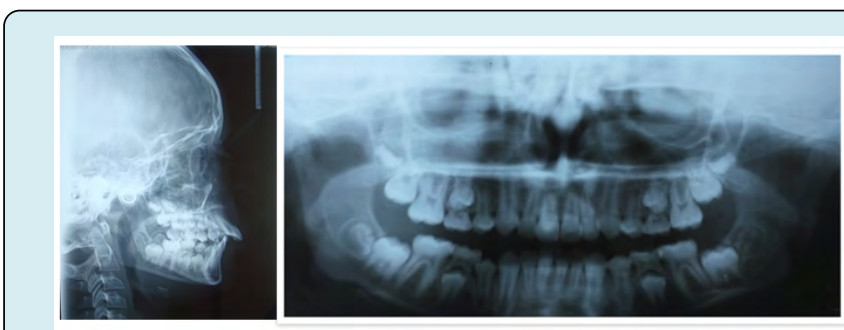

Figure 2: Pretreatment OPG and cephalogram.

Cephalometric STEINER and TWEED analysis revealed a skeletal class II discrepancy with biprotrusion of the central upper and lower incisors and a class II canine and molar relationship (Table 1 ).

\begin{tabular}{|c|c|c|}
\hline Steiner analysis & Objectives & Pre-TRT \\
\hline SNA & $82^{\circ}$ & $79^{\circ}$ \\
\hline SNB & $80^{\circ}$ & $76^{\circ}$ \\
\hline ANB & $2^{\circ}$ & $3^{\circ}$ \\
\hline SND & $76^{\circ}$ & $73^{\circ}$ \\
\hline I/NA & $22^{\circ}$ & $39^{\circ}$ \\
\hline I/NA mm & $4 \mathrm{~mm}$ & $11 \mathrm{~mm}$ \\
\hline $\mathrm{i} / \mathrm{NB}$ & $25^{\circ}$ & $35^{\circ}$ \\
\hline $\mathrm{i} / \mathrm{NB} \mathrm{mm}$ & $4 \mathrm{~mm}$ & $6 \mathrm{~mm}$ \\
\hline $\mathrm{I} / \mathrm{i}$ & $131^{\circ}$ & $104^{\circ}$ \\
\hline Pog/NB & I & $2 \mathrm{~mm}$ \\
\hline Occ/SN & $14^{\circ}$ & $17^{\circ}$ \\
\hline GoGn/SN & $32^{\circ}$ & $29^{\circ}$ \\
\hline Tweed analysis & Objectives & Pre-TRT \\
\hline FMA & $25^{\circ} \pm 3$ & $15^{\circ}$ \\
\hline FMIA & $67^{\circ} \pm 3$ & $56^{\circ}$ \\
\hline IMPA & $88^{\circ} \pm 3$ & $109^{\circ}$ \\
\hline SNA & $82^{\circ}$ & $79^{\circ}$ \\
\hline SNB & $80^{\circ}$ & $76^{\circ}$ \\
\hline ANB & $2^{\circ} \pm 2$ & $3^{\circ}$ \\
\hline AoBo & $-2 \mathrm{~mm}$ à +2 & $3,5 \mathrm{~mm}$ \\
\hline Occl to PF & $10^{\circ}$ & $0,5^{\circ}$ \\
\hline Angle Z & $75^{\circ} \pm 5$ & $72^{\circ}$ \\
\hline Upper Lip & 1 & $11 \mathrm{~mm}$ \\
\hline Total Chin & 1 & $12 \mathrm{~mm}$ \\
\hline PFH & $45 \mathrm{~mm}$ & $40 \mathrm{~mm}$ \\
\hline $\mathrm{AFH}$ & $65 \mathrm{~mm}$ & $60 \mathrm{~mm}$ \\
\hline Index FHI & 0.69 & 0.66 \\
\hline
\end{tabular}

Table1: Pre-treatment cephalometric analysis. 


\section{Treatment Objectives}

Treatment goals aimed to establish a normal anterior and canine occlusion, to establish class I molar and canine relationship, to improve facial and smile aesthetics and finally to achieve a good and stable dentoalveolar changes.

\section{Treatment Possibilities}

Since the patient was in pre pubertal growth stage, two treatment options were discussed, the first one is a functional treatment associated with orthodontic treatment or an orthodontic treatment with class II mechanics only.

\section{Treatment Progress}

During the orthopedic phase we implemented a class II Monobloc activator with extraoral forces worn for 6 months, 14 hours per day witch helped attain class I canine and molar relationship (Figure 3).

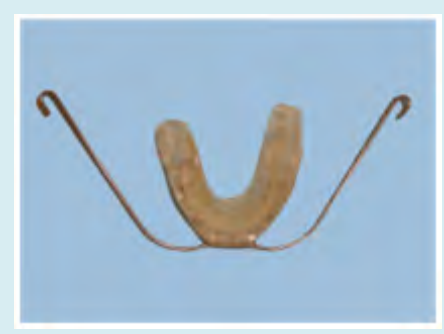

Figure 3: Monobloc activator.

At the end of this phase, intraoral examination showed a correction of the midline shift, the class I molar was achieved on both sides whereas a minor class II canine remained on the right side, we noted a reduction of the over jet to $2 \mathrm{~mm}$ and an improvement of the overbite (Figure 4).

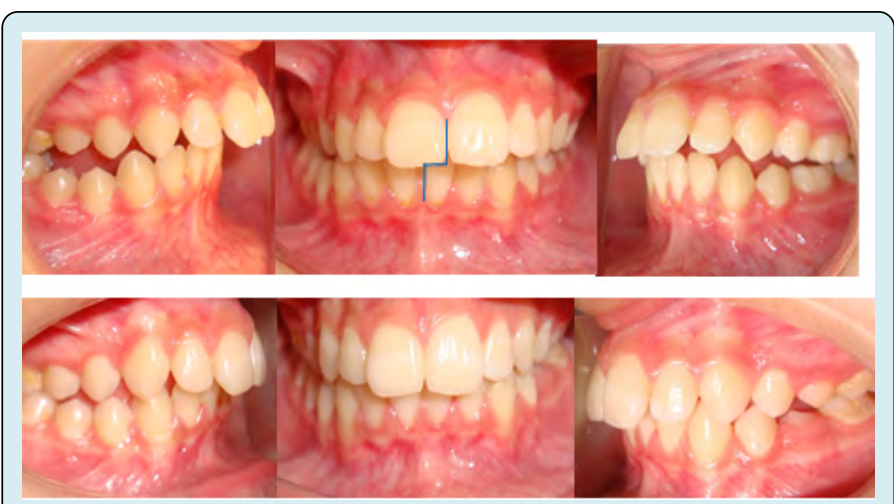

Figure 4: Post activator dento-alveolar changes.
A noticeable improvement of the profile was noted as the nasolabial angle increased due to the uprighting of the upper central incisors, the patient grew more chin tissues and bit no more his lower lip (Figures 5-9).

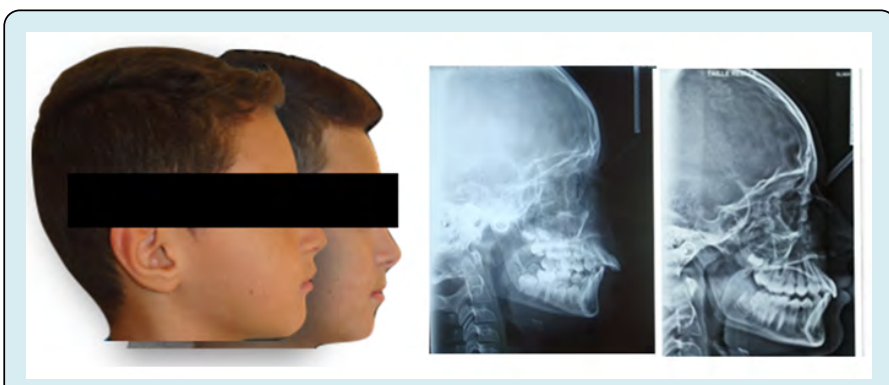

Figure 5: Post activator photographs and cephalogram pre and post activator.

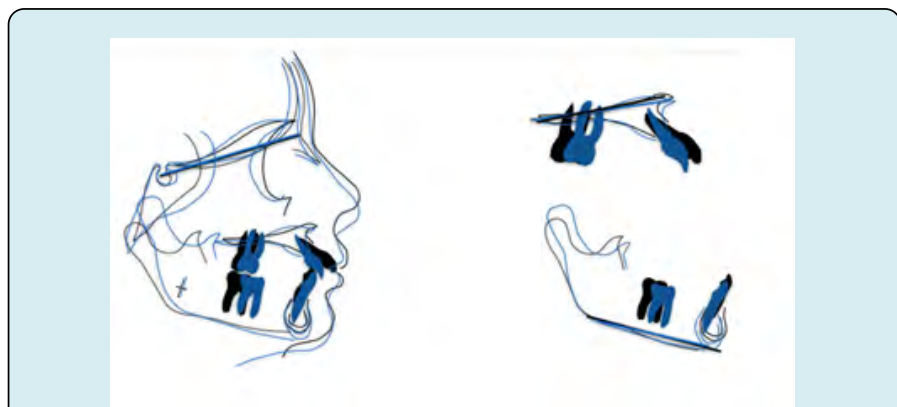

Figure 6: Superimpositions before and after using the activator.

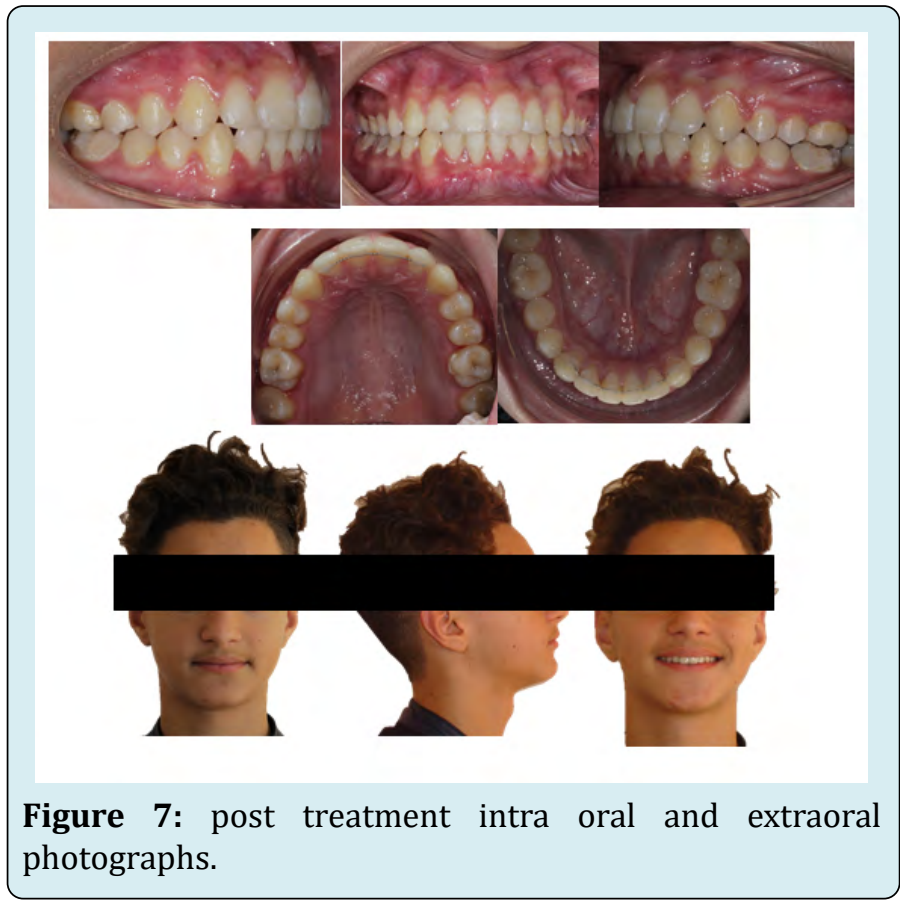



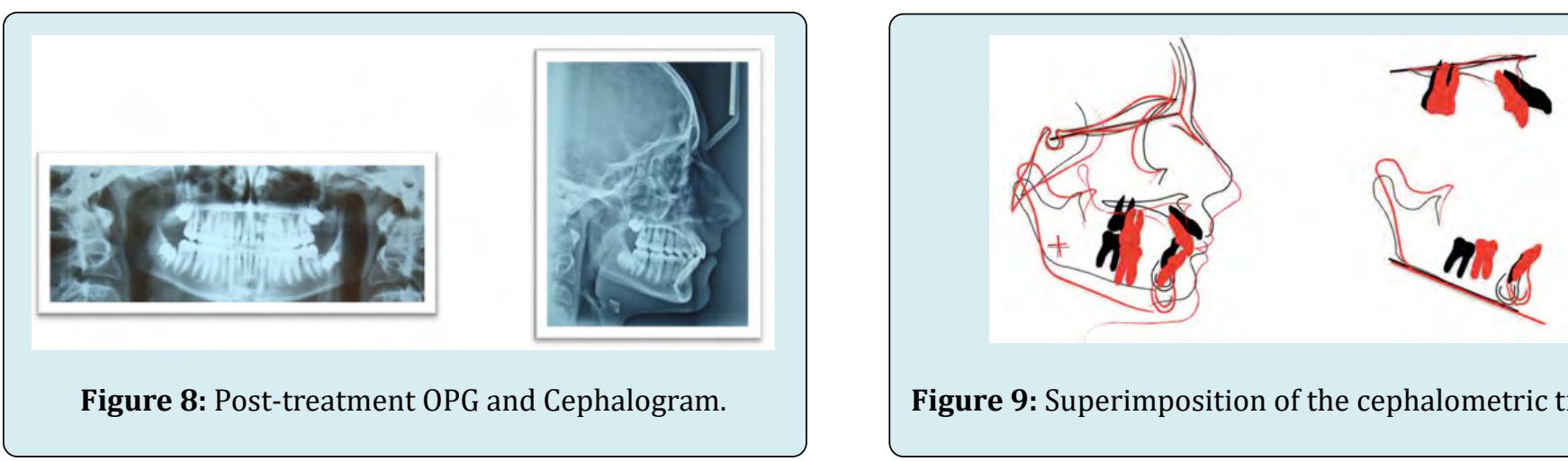

Figure 9: Superimposition of the cephalometric tracings.

\begin{tabular}{|c|c|c|c|}
\hline Steiner analysis & Objectives & Pre-TRT & Post-activator \\
\hline SNA & $82^{\circ}$ & $79^{\circ}$ & 81 \\
\hline SNB & $80^{\circ}$ & $76^{\circ}$ & 79 \\
\hline ANB & $2^{\circ}$ & $3^{\circ}$ & $2^{\circ}$ \\
\hline SND & $76^{\circ}$ & $73^{\circ}$ & 76 \\
\hline $\mathrm{I} / \mathrm{NA}$ & $22^{\circ}$ & $39^{\circ}$ & $25^{\circ}$ \\
\hline $\mathrm{I} / \mathrm{NA} \mathrm{mm}$ & $4 \mathrm{~mm}$ & $11 \mathrm{~mm}$ & $6 \mathrm{~mm}$ \\
\hline i/NB & $25^{\circ}$ & $35^{\circ}$ & $30^{\circ}$ \\
\hline $\mathrm{i} / \mathrm{NB} \mathrm{mm}$ & $4 \mathrm{~mm}$ & $6 \mathrm{~mm}$ & $4 \mathrm{~mm}$ \\
\hline $\mathrm{I} / \mathrm{i}$ & $131^{\circ}$ & $104^{\circ}$ & $120^{\circ}$ \\
\hline Pog/NB & & $2 \mathrm{~mm}$ & $1 \mathrm{~mm}$ \\
\hline Occ/SN & $14^{\circ}$ & $17^{\circ}$ & 16 \\
\hline GoGn/SN & $32^{\circ}$ & $29^{\circ}$ & $30^{\circ}$ \\
\hline Tweed analysis & Objectives & Pre-TRT & Post-activator \\
\hline FMA & $25^{\circ} \pm 3$ & $15^{\circ}$ & $20^{\circ}$ \\
\hline FMIA & $67^{\circ} \pm 3$ & $56^{\circ}$ & $58^{\circ}$ \\
\hline IMPA & $88^{\circ} \pm 3$ & $109^{\circ}$ & $102^{\circ}$ \\
\hline SNA & $82^{\circ}$ & $79^{\circ}$ & 81 \\
\hline SNB & $80^{\circ}$ & $76^{\circ}$ & 79 \\
\hline ANB & $2^{\circ} \pm 2$ & $3^{\circ}$ & $2^{\circ}$ \\
\hline AoBo & $-2 m m$ à +2 & $3,5 \mathrm{~mm}$ & $0 \mathrm{~mm}$ \\
\hline Occl to PF & $10^{\circ}$ & $0,5^{\circ}$ & $5^{\circ}$ \\
\hline Angle Z & $75^{\circ} \pm 5$ & $72^{\circ}$ & $73^{\circ}$ \\
\hline Upper Lip & 1 & $11 \mathrm{~mm}$ & $10 \mathrm{~mm}$ \\
\hline Total Chin & 1 & $12 \mathrm{~mm}$ & $12 \mathrm{~mm}$ \\
\hline PFH & $45 \mathrm{~mm}$ & $40 \mathrm{~mm}$ & $39 \mathrm{~mm}$ \\
\hline AFH & $65 \mathrm{~mm}$ & $60 \mathrm{~mm}$ & $56 \mathrm{~mm}$ \\
\hline Index FHI & 0.69 & 0.66 & 0,69 \\
\hline
\end{tabular}

Table 2: Post-activator cephalometric analysis.

Cephalometric data during this first phase is represented in Table 2.
Superimpositions of the cepahlograms before and after using the Monobloc activator showed an uprighting of the 
upper incisors and a maintain of the lower incisor position and of the vertical facial dimension.

After the orthopedic phase, an orthodontic treatment was conducted with an aim to align the arches and to correct dental rotations using edgewise appliance with an overall duration of 18 months. This treatment included three phases: the first stage aimed the alignment and leveling of the maxillary and mandibular arch using NiTi arches, followed by a correction of the rotations, class II elastics and finally finishing and intermaxillary digitation with rigid rectangular arches. All treatment objectives were achieved, class I molar and canine relationship was satisfactory, a good alignment of the arches was obtained and the overall facial aesthetics was improved.

Post treatment cephalometric data are represented in Table 3.

\begin{tabular}{|c|c|c|c|c|}
\hline Steiner analysis & Objective & Pre-TRT & Post activator & Post Trt \\
\hline SNA & $82^{\circ}$ & $79^{\circ}$ & 81 & $80^{\circ}$ \\
\hline SNB & $80^{\circ}$ & $76^{\circ}$ & 79 & $76^{\circ}$ \\
\hline ANB & $2^{\circ}$ & $3^{\circ}$ & $2^{\circ}$ & $4^{\circ}$ \\
\hline SND & $76^{\circ}$ & $73^{\circ}$ & 76 & $75^{\circ}$ \\
\hline $\mathrm{I} / \mathrm{NA}$ & $22^{\circ}$ & $39^{\circ}$ & $25^{\circ}$ & $20^{\circ}$ \\
\hline $\mathrm{I} / \mathrm{NA} \mathrm{mm}$ & $4 \mathrm{~mm}$ & $11 \mathrm{~mm}$ & $6 \mathrm{~mm}$ & $4 \mathrm{~mm}$ \\
\hline $\mathrm{i} / \mathrm{NB}$ & $25^{\circ}$ & $35^{\circ}$ & $30^{\circ}$ & $31^{\circ}$ \\
\hline $\mathrm{i} / \mathrm{NB} \mathrm{mm}$ & $4 \mathrm{~mm}$ & $6 \mathrm{~mm}$ & $4 \mathrm{~mm}$ & $5 \mathrm{~mm}$ \\
\hline $\mathrm{I} / \mathrm{i}$ & $131^{\circ}$ & $104^{\circ}$ & $120^{\circ}$ & $125^{\circ}$ \\
\hline Pog/NB & & $2 \mathrm{~mm}$ & $1 \mathrm{~mm}$ & $1 \mathrm{~mm}$ \\
\hline Occ/SN & $14^{\circ}$ & $17^{\circ}$ & 16 & $11,5^{\circ}$ \\
\hline GoGn/SN & $32^{\circ}$ & $29^{\circ}$ & $30^{\circ}$ & $32^{\circ}$ \\
\hline Tweed analysis & Objectives & Pre-TRT & Post-activator & Post Trt \\
\hline FMA & $25^{\circ} \pm 3$ & $15^{\circ}$ & $20^{\circ}$ & $20^{\circ}$ \\
\hline FMIA & $67^{\circ} \pm 3$ & $56^{\circ}$ & $58^{\circ}$ & $58^{\circ}$ \\
\hline IMPA & $88^{\circ} \pm 3$ & $109^{\circ}$ & $102^{\circ}$ & $102^{\circ}$ \\
\hline SNA & $82^{\circ}$ & $79^{\circ}$ & 81 & $80^{\circ}$ \\
\hline SNB & $80^{\circ}$ & $76^{\circ}$ & 79 & $76^{\circ}$ \\
\hline ANB & $2^{\circ} \pm 2$ & $3^{\circ}$ & $2^{\circ}$ & $4^{\circ}$ \\
\hline AoBo & $-2 m m+2$ & $3,5 \mathrm{~mm}$ & $0 \mathrm{~mm}$ & $2 \mathrm{~mm}$ \\
\hline Occl to PF & $10^{\circ}$ & $0,5^{\circ}$ & $5^{\circ}$ & $3^{\circ}$ \\
\hline Angle Z & $75^{\circ} \pm 5$ & $72^{\circ}$ & $73^{\circ}$ & $82^{\circ}$ \\
\hline Upper Lip & 1 & $11 \mathrm{~mm}$ & $10 \mathrm{~mm}$ & $10 \mathrm{~mm}$ \\
\hline Total Chin & 1 & $12 \mathrm{~mm}$ & $12 \mathrm{~mm}$ & $13 \mathrm{~mm}$ \\
\hline PFH & $45 \mathrm{~mm}$ & $40 \mathrm{~mm}$ & $39 \mathrm{~mm}$ & $62 \mathrm{~mm}$ \\
\hline $\mathrm{AFH}$ & $65 \mathrm{~mm}$ & $60 \mathrm{~mm}$ & $56 \mathrm{~mm}$ & $44 \mathrm{~mm}$ \\
\hline Index FHI & 0.69 & 0.66 & 0,69 & 0,70 \\
\hline
\end{tabular}

Table 3: Post-treatment cephalometric analysis.

Superimposition of the cephalometric tracings showed a harmonious maxillary and mandible relationship, with a forward movement of the chin, an upright and intrusion of the upper incisor a maintain of the position of the lower incisor and a clockwise rotation.

\section{Discussion}

Class II malocclusions might have several combinations of skeletal and dento-alveolar components, thus understanding the etiology and the differential diagnosis is 
essential to decide whether it is an orthodontic, orthopedic, surgical treatment or a combination of these treatment modalities. However, from an etiological point of view it is generally believed that a skeletal class II is often caused by a combination of mandibular deficiency and a maxillary excess, thus a combined treatment might be a better option to achieve dento alveolar and skeletal equilibrium [10]. Several studies showed that the main reason for using functional removable appliances is to establish muscular balance, eliminate oral dysfunction and allow a proper length of the maxilla and the mandible [1]. These devices have one thing in common they induce the mandible into an anterior position as a part of the overall treatment effect, They apply constant forces to muscular environment that causes posture modification, and a change in functions and forces on the dento alveolar arches through the muscles [11].

In our case, we treated a growing class II patient with combined therapy using monobloc activator and orthodontic treatment. First phase results showed satisfactory esthetic and dento alveolar changes, mostly a correction of the molar and canine class II, a correction of the midline shift and a considerable reduction of the overjet due to the up righting of the upper incisors and a forward positioning of the mandible and an improvement of the soft tissue profile due to more favorable soft tissue behavior [11].

\section{Conclusion}

A satisfactory esthetic and functional result was achieved for this patient due to employing a two phase treatment protocol that was tailored specifically to this patient's need. This approach took advantage of patient's growth which helped to achieve a significant sagittal correction. Our case illustrates the need for understanding the etiology and therefore implementing the right treatment protocol rather than a cookbook approach in the management of these discrepancies.

\section{References}

1. Rédua RB (2020) Different approaches to the treatment of skeletal Class II malocclusion during growth: Bionator versus extraoral appliance. Dental Press J Orthod 25(2): 69-85.
2. Kalha AS (2014) Early orthodontic treatment reduced incisal trauma in children with Class II malocclusions. Evid Based Dent 15(1): 18-20.

3. Krooks L, Pirttiniemi P, Tolvanen M, Kanavakis G, Lähdesmäki R, et al. (2019) Association of facial sagittal and vertical characteristics with facial aesthetics in the Northern Finland Birth Cohort 1966. Eur J Orthod 41(3): 279-285.

4. Dutra SR, Pretti H, Martins MT, Bendo CB, Vale MP (2018) Impact of malocclusion on the quality of life of children aged 8 to 10 years. Dental Press J Orthod 23(2): 46-53.

5. Choi YJ, Chung CJ, Kim KH (2015) Periodontal consequences of mandibular incisor proclination during presurgical orthodontic treatment in Class III malocclusion patients. Angle Orthod 85(3): 427-433.

6. Martins OFM, Chaves Junior CM, Rossi RRP, Cunali PA, Dal Fabro C (2018) Side effects of mandibular advancement splints for the treatment of snoring and obstructive sleep apnea: a systematic review. Dental Press J Orthod 23(4): 45-54.

7. Mc Lain JB, Proffit WR (1985) Oral health status in the United States: prevalence of malocclusion. J Dent Educ 49(6): 386-396.

8. Proffit WR, Fields HW, Moray LJ (1998) Prevalence of malocclusion and orthodontic treatment need in the United States: estimates from the N-HANES III survey. Int J Adult Orthod Orthog Surg 13(2): 97-106.

9. Santamaría Villegas A, Manrique Hernandez R, Alvarez Varela E, Restrepo Serna C (2017) Effect of removable functional appliances on mandibular length in patients with class II with retrognathism: systematic review and meta-analysis. BMC Oral Health 17(1): 52.

10. Sharma NS (2013) Management of a growing Skeletal Class II Patient: A Case Report. Int J Clin Pediatr Dent 6(1): 48-54.

11. Lapter Varga M (2012) Removable orthodontic therapyClinics or/and science. The work of the Croatian Academy of Sciences and Arts. Medical Sciences pp: 117-126. 